\title{
Research on Communication Identification of Intangible Cultural Heritage Popular Science Publication Based on AHP and Entropy Method
}

\author{
Yun Zhu, Hui Ye, Shukun Tang \\ School of Public Affairs of the University of Science and Technology of China, Hefei, China \\ Email: zhuyun89@mail.ustc.edu.cn
}

How to cite this paper: Zhu, Y., Ye, H. and Tang, S.K. (2017) Research on Communication Identification of Intangible Cultural Heritage Popular Science Publication Based on AHP and Entropy Method. Open Journal of Social Sciences, 5, 199-208. https://doi.org/10.4236/jss.2017.58016

Received: July 18, 2017

Accepted: August 12, 2017

Published: August 15, 2017

Copyright (c) 2017 by authors and Scientific Research Publishing Inc. This work is licensed under the Creative Commons Attribution International License (CC BY 4.0). http://creativecommons.org/licenses/by/4.0/

\begin{abstract}
Based on "uses and gratifications theory", the authors build an evaluation model of the communication identification of intangible cultural heritage (ICH) popular science publication. The weighed score of the model is obtained according to experts and general audience survey. The result is as follow: the factors at all the levels of use and identification affect audience identification in the evaluation model of communication identification of ICH popular science publication. Among these factors, audience from whom to know this channel, clear demonstration and integrating into relevant situation of skills and knowledge, these three indicators have significant influence on the communication identification of ICH popular science publication. It not only helps audience to obtain knowledge, but also generates audiences' interests and making a combination between new media and themselves by other people.
\end{abstract}

\section{Keywords}

Popular Science Publication, Use and Gratification, AHP, Entropy Method, Identification

\section{Introduction}

As one of the communication channels, publication has significant effects in the communication process. With the development of society, whatever the types of publication are, what the audiences concern the most is whether the contents can be presented properly, reading comfort level and whether it can inspire interests [1]. In new media communication age, information communication changes from mass communication to personalized precise communication [2]. 
Getting more concerning from people, as one of the most important channel of ICH popular science, publication must be evaluated precisely from the aspect of audience. Then it will be evaluated properly in audience identification.

From literature review, most researchers focus on communication and inheritance of ICH from the aspect of communication and ICH in contemporary media. The research of communication and inheritance of ICH are mainly from the aspect of communication [3] [4] [5]. Contemporary media mainly discuss its influence and effects in modern communication [6] [7] [8] [9] [10]. Therefore, no one has conducted research on ICH popular science publication. Besides, no one has measured the communication effects or traditional identification by putting inheritors and general audience into one index. In this article, questionnaire method is used about ICH popular science publication in inheritors and general audience respectively. The result is calculated on the basis of AHP and entropy method. Then index system of communication identification of ICH popular science publication is built to provide reference to other ICH popular science publication and other general popular science publication.

\section{Building Index System of Communication Identification of ICH Popular Science Publication}

Only can maintain active culturally and inherit specific cultural significance and cultural symbol in dynamic communication, media have important effects in its communication process. As one of the important channel of media communication, the author chooses ICH popular science publication as a pointcut in publication. Based on "uses and gratifications theory", an index system of communication identification of ICH popular science publication is built.

\subsection{Uses}

In the book "Personal Influence, The part played by people in the flow of mass communications", Katz believes that needs of individuals are stimulated by social and psychological factors. Needs arouse individuals' expectation towards mass communication or other media. Different expectation leads to different contact and use. The use of media satisfies the needs of individuals [11]. In this article, first-level index is designed as "use" and second-level indexes are designed as using habits and using behavior. As for using habits, third-level indexes are daily habits, holiday habits, frequency of usage, durable years. As for using behavior, third-level index is from whom the audience knows this channel.

\subsection{Identification}

In this article, the index of "gratification" is designed as "identification" in the index system. It is the first-level index. Because "identification" can illustrate audience's aspiration and satisfaction degree better than "gratification" in the communication of ICH popular science publication. Therefore, second-level indexes of "identification" are satisfaction degree and dependency degree. As for 
satisfaction degree, third-level indexes are clear demonstration, acquiring knowledge and integrating into relevant situation of skills and knowledge. As for dependency degree, third-level indexes are as follow: 1) audience always think of relevant knowledge when they do not use it; 2) it is used as the methods of reducing pressure, disencumbering, relieving anxiety and dilemma, and looking for emotional sustenance; 3) it is often used overtime; 4) other tasks at hand cannot be completed due to reading ICH popular science publication; 5) cognition about ICH mainly comes from ICH popular science publication; 6) audience look for relevant knowledge or travel to relevant places because they have read ICH popular science publication. According to the first-level indexes (criterion layer), second-level indexes (factor layer) and third-level indexes (index layer), the index system of communication identification of ICH popular science publication (Table 1) is built.

\section{Building Index System of Communication Identification of ICH Popular Science Publication Based on AHP and Entropy Method}

\subsection{Evaluation Model of Communication Identification of ICH Popular Science Publication Based on AHP}

AHP is a decision-making method combining qualitative and quantitative analyzing. Its basis idea is as follow: analyzing deeply about complex and difficult

Table 1. Index system of communication identification of ICH popular science publication.

\begin{tabular}{|c|c|c|c|}
\hline Objective level & $\begin{array}{l}\text { Criterion } \\
\text { layer }\end{array}$ & Factor layer & Index layer \\
\hline \multirow{19}{*}{$\begin{array}{l}\text { Index system of } \\
\text { communication } \\
\text { identification of } \\
\text { ICH popular } \\
\text { science } \\
\text { publication }\end{array}$} & \multirow{7}{*}{ Use } & \multirow{4}{*}{$\begin{array}{l}\text { U1 using } \\
\text { habits }\end{array}$} & U11 daily habits \\
\hline & & & U12 holiday habits \\
\hline & & & U13 frequency of usage \\
\hline & & & U14 durable years \\
\hline & & \multirow{3}{*}{$\begin{array}{l}\mathrm{U} 2 \text { using } \\
\text { behavior }\end{array}$} & U21 from whom the audience \\
\hline & & & knows this channel \\
\hline & & & G11 clear demonstration \\
\hline & \multirow{12}{*}{ Identification } & \multirow{3}{*}{$\begin{array}{l}\text { G1 satisfaction } \\
\text { degree }\end{array}$} & G12 acquiring knowledge \\
\hline & & & G13 integrating into relevant situation \\
\hline & & & of skills and knowledge \\
\hline & & \multirow{9}{*}{$\begin{array}{c}\text { G2 dependency } \\
\text { degree }\end{array}$} & G21 other tasks at hand cannot be \\
\hline & & & completed due to reading ICH \\
\hline & & & popular science publication \\
\hline & & & G22 cognition about ICH mainly \\
\hline & & & comes from ICH popular science \\
\hline & & & publication \\
\hline & & & G23 audience look for relevant \\
\hline & & & knowledge or travel to relevant places \\
\hline & & & $\begin{array}{l}\text { because they have read ICH popular } \\
\text { science publication }\end{array}$ \\
\hline
\end{tabular}


problems, influencing factors and their intrinsic relations; then building a hierarchical structure model; after that, making thinking process of decision makers hierarchical and mathematical. To be specific, AHP aims to resolve the problems into several indexes and group these indexes according to dominance relation, and then link then into an orderly class hierarchy. It usually contains objective level, criterion layer and factor layer. Experts or decision makers make pairwise comparison among all the factors in the same control indicators. The importance of indexes in each level can be determined in this way. Then indexes will be weighed by each level and index weight can be determined [12] [13]. The author conducted interviews among 10 experts in ICH research from ICH training workshop of Ministry of Culture. These experts are asked to judge the importance of factors. Results are as follow:

1) Component weight analysis

Component factors (use and identification) of communication identification in ICH popular science publication are marked as " $U$ " and " $G$ ". One of the component factors is set as " $\mathrm{A}$ ", that is " $\mathrm{U}$ " or " $\mathrm{G}$ ".

$\lambda \max =3.0044, \mathrm{CR}=0.0043<0.1$, The consistency of matrix $\mathrm{A}$ is judges as undergoing test (Table 2).

2) Using weight determination

Using component factors are marked as "U1" and "U2".

When $\lambda \max =2.0055, C R=0.0019<0.1$, the consistency of matrix $U$ is judges as undergoing test (Table 3 ).

a) Using habits weight determination

Component factors of using habits are marked as "U11", "U12", "U13" and "U14".

When $\lambda \max =4.1240, \mathrm{CR}=0.0464<0.1$, the consistency of matrix U1 is judges as undergoing test (Table 4).

b) Using behavior weight determination

Component factors of using behavior are marked as "U21".

When $\lambda \max =2.2260, C R=0.0333<0.1$, the consistency of matrix U2 is judges as undergoing test (Table 5).

3) Identification weight determination

Component factors of identification are marked as "G1" and "G2".

Table 2. Analysis table of survey data (1).

\begin{tabular}{ccc}
\hline$A$ & U & G \\
\hline U & 1 & $1 / 3$ \\
$-G$ & 3 & 1 \\
\hline
\end{tabular}

Table 3. Analysis table of survey data (2).

\begin{tabular}{ccc}
\hline $\mathrm{U}$ & $\mathrm{U} 1$ & $\mathrm{U} 2$ \\
\hline $\mathrm{U} 1$ & 1 & 5 \\
$\mathrm{U} 2$ & $1 / 5$ & 1 \\
\hline
\end{tabular}


Table 4. Analysis table of survey data (3).

\begin{tabular}{ccccc}
\hline U1 & U11 & U12 & U13 & U14 \\
\hline U11 & 1 & $1 / 2$ & 5 & 3 \\
U12 & $1 / 5$ & $1 / 3$ & 1 & 2 \\
U13 & $1 / 3$ & $1 / 4$ & $1 / 2$ & 1 \\
U14 & 2 & 1 & 3 & 4 \\
\hline
\end{tabular}

Table 5. Analysis table of survey data (4).

\begin{tabular}{cc}
\hline $\mathrm{U} 2$ & $\mathrm{U} 21$ \\
\hline $\mathrm{U} 21$ & $1 / 3$ \\
\hline
\end{tabular}

When $\lambda \max =6.8367, \mathrm{CR}=0.0903<0.1$, the consistency of matrix $\mathrm{G}$ is judges as undergoing test (Table 6).

a) Satisfaction degree weight determination

Component factors of satisfaction degree are marked as "G11", "G12" and "G13".

When $\lambda \max =3.9203, \mathrm{CR}=0.09152<0.1$, the consistency of matrix G1 is judges as undergoing test (Table 7).

b) Dependence degree weight determination

Component factors of dependence degree are marked as "G21", "G22" and "G23".

When $\lambda \max =6.5712, \mathrm{CR}=0.08774<0.1$, the consistency of matrix G2 is judges as undergoing test (Table 8).

To sum up, the level order of ICH popular science publication is in Table 9 according to the data:

In consequence, the main evaluation indexes that influence the communication identification of $\mathrm{ICH}$ popular science publication are as follow: from whom the audience knows this channel; acquiring knowledge; integrating into relevant situation of skills and knowledge.

\subsection{Evaluation Model of Communication Identification of ICH Popular Science Publication Based on Entropy Method}

According to index system of communication identification of ICH popular science publication, a questionnaire survey has been conducted. In the survey, audiences are asked to rate indexes. The specific steps are as follow. First, questionnaires were handed out to the audience. Then, audiences were asked to rate three-grade indexes on a 0 - 100 scale. In order to make a convenient comparison, each 5 scores is divided into a level, of which full mark is 100 and pass mark is 60 . After collecting questionnaire data, it is evaluated by entropy method according to index system of communication identification of ICH popular science publication. From September 22 to 24 in 2016, the survey was conducted among 300 audiences who were selected from the fourth China ICH Fair in Jinan when they were reading or buying ICH popular science books. 210 valid questionnaires 
Table 6. Analysis table of survey data (5).

\begin{tabular}{ccc}
\hline G & G1 & G2 \\
\hline G1 & $1 / 3$ & 3 \\
G2 & $1 / 2$ & 5 \\
\hline
\end{tabular}

Table 7. Analysis table of survey data (6).

\begin{tabular}{cccc}
\hline G1 & G11 & G12 & G13 \\
\hline G11 & $1 / 2$ & $1 / 3$ & 3 \\
G12 & 2 & 1 & 3 \\
G13 & $1 / 5$ & $1 / 3$ & 1 \\
\hline
\end{tabular}

Table 8. Analysis table of survey data (7).

\begin{tabular}{cccc}
\hline G2 & G21 & G22 & G23 \\
\hline G21 & 3 & $1 / 3$ & $1 / 2$ \\
G22 & 2 & 3 & 3 \\
G23 & $1 / 3$ & 1 & $1 / 3$ \\
\hline
\end{tabular}

Table 9. Level order of ICH popular science publication.

\begin{tabular}{|c|c|c|c|c|c|c|c|}
\hline $\begin{array}{c}\text { Evaluation } \\
\text { objective }\end{array}$ & $\begin{array}{c}\text { First-leve } \\
\text { l index }\end{array}$ & $\begin{array}{l}\text { Weight } \\
\text { WCi }\end{array}$ & $\begin{array}{l}\text { Second-le } \\
\text { vel index }\end{array}$ & $\begin{array}{l}\text { Weigh } \\
\text { t WCi }\end{array}$ & $\begin{array}{l}\text { Third-lev } \\
\text { el index }\end{array}$ & $\begin{array}{l}\text { Weight } \\
\text { WCi }\end{array}$ & Wij \\
\hline \multirow{11}{*}{$\begin{array}{l}\text { Index system of } \\
\text { cultural } \\
\text { transmission } \\
\text { path } \\
\text { identification }\end{array}$} & \multirow{5}{*}{$\mathrm{U}$} & \multirow{5}{*}{0.627} & \multirow{4}{*}{$\mathrm{U} 1$} & \multirow{4}{*}{0.351} & U11 & 0.341 & 0.120 \\
\hline & & & & & U12 & 0.198 & 0.138 \\
\hline & & & & & U13 & 0.472 & 0.137 \\
\hline & & & & & U14 & 0.406 & 0.211 \\
\hline & & & \multirow[t]{2}{*}{$\mathrm{U} 2$} & \multirow[t]{2}{*}{0.631} & $\mathrm{U} 21$ & 0.631 & 0.282 \\
\hline & \multirow{6}{*}{ G } & \multirow{6}{*}{0.297} & & & G11 & 0.482 & 0.105 \\
\hline & & & \multirow[t]{2}{*}{ G1 } & \multirow[t]{2}{*}{0.310} & G12 & 0.525 & 0.257 \\
\hline & & & & & G13 & 0.439 & 0.239 \\
\hline & & & \multirow{3}{*}{ G2 } & \multirow{3}{*}{0.247} & G21 & 0.168 & 0.214 \\
\hline & & & & & G22 & 0.256 & 0.153 \\
\hline & & & & & G23 & 0.103 & 0.136 \\
\hline
\end{tabular}

a. Numbers in this table reserve three decimal fractions.

were collected. Then the collected data was analyzed using entropy method (Table 10).

According to Table 10, the main evaluation indexes that influence the communication identification of ICH popular science publication are as follow: from whom the audience knows this channel; acquiring knowledge; integrating into relevant situation of skills and knowledge.

\subsection{Calculation of Index Factor Weight}

On the basis of the text above, the calculation formula of communication identi- 
Table 10. Entropy weight order of communication identification of ICH popular science publication.

\begin{tabular}{ccc}
\hline Third-level index & Entropy Value Si & Weight Wi \\
\hline U11 & 0.646 & 0.048 \\
U12 & 0.672 & 0.076 \\
U13 & 0.647 & 0.075 \\
U14 & 0.628 & 0.081 \\
U21 & 0.655 & 0.088 \\
G11 & 0.683 & 0.039 \\
G12 & 0.629 & 0.085 \\
G13 & 0.628 & 0.085 \\
G21 & 0.628 & 0.083 \\
G22 & 0.617 & 0.079 \\
G23 & 0.639 & 0.073 \\
\hline
\end{tabular}

Numbers in this table reserve three decimal fractions.

fication of ICH popular science publication score is [5]: $\omega_{t}=\omega_{A H P}+(1-\alpha) \omega_{e}$, where $0 \leq \alpha \leq 1, \omega_{A H P}$ is score product of weight from AHP and score from experts, $\alpha$ is proportional coefficient between AHP and entropy method. Combining experts and audiences' opinion, $\alpha$ is set as 0.5 .

In summary, Table 11 shows that getting the highest score, from whom the audience knows this channel, acquiring knowledge, integrating into relevant situation of skills and knowledge, these three indexes have significant influence on the communication identification of ICH popular science publication.

\section{Results}

\subsection{Use}

In the communication identification process of $\mathrm{ICH}$ popular science publication, audience pays a lot of attention in whether its forms agree with their own needs and interests. From using factors, audience can acquire intuitive impression of various experiences. So using factors have important influence on the communication identification process of ICH popular science publication.

\subsubsection{Using Habits}

ICH popular science publication builds experience environment and provides audience feedbacks, which not only helps audience obtain knowledge, but also generates audiences' interests based on their own using habits, and inspires their motivation and impulsion of acquiring knowledge. Therefore, audiences' using habits are important. Different using habits will affect audiences' identification to a great degree in the communication identification process of ICH popular science publication.

\subsubsection{Using Behavior}

As for using behavior, audience can make a combination between new media 
Table 11. Total score of third-indexes of communication identification of ICH popular science publication.

\begin{tabular}{cccc}
\hline Third-level index & $\omega_{\text {AHP }}$ & $\omega_{\mathrm{e}}$ & $\omega_{\mathrm{t}}$ \\
\hline U11 & 0.120 & 0.048 & 0.084 \\
U12 & 0.138 & 0.076 & 0.107 \\
U13 & 0.137 & 0.075 & 0.106 \\
U14 & 0.211 & 0.081 & 0.146 \\
U21 & 0.282 & 0.088 & 0.185 \\
G11 & 0.105 & 0.039 & 0.072 \\
G12 & 0.257 & 0.085 & 0.171 \\
G13 & 0.239 & 0.085 & 0.162 \\
G21 & 0.214 & 0.083 & 0.149 \\
G22 & 0.153 & 0.079 & 0.116 \\
G23 & 0.136 & 0.073 & 0.105 \\
\hline
\end{tabular}

Numbers in this table reserve three decimal fractions.

and themselves by other people. They can master experience from others' knowledge, which leads to the spiral growth of identification. From the data in the model, we know that using behavior of audience also affect audiences' identification to a great extent.

\subsection{Identification}

Because of easy-to-understand advantages, ICH popular science publication attracts a lot of audience's attention and obtains their identification. The combination of satisfaction degree and dependence degree constitute second-level indexes. In the communication identification of ICH popular science publication, identification affects it in deep degree.

\subsubsection{Satisfaction Degree}

ICH popular science publication is different from other publication in that the former one spread knowledge and culture connotation, which is the invisible product. So satisfaction degree of audiences is especially important. As for using behavior, audience can make a combination between new media and themselves by other people. They can master experience from others' knowledge, which leads to the spiral growth of identification. Therefore, satisfaction degree can improve audiences' identification. It has great influence on the communication identification of ICH popular science publication.

\subsubsection{Dependence Degree}

By giving audience dependence, ICH popular science publication constructs positive emotion experience, where audience experiences this kind of dependence in the media communication path. Among all the factors in the communication identification of ICH popular science publication, audiences' emotional experience is the most prominent. When keeping in touch and interacting with 
publication, audience will generate strong dependence emotional experience consciously or unconsciously. When communication carrier is similar or same, the audience leans to choose the products which can make them feel good and maintain lasting loyalty. In this way they have great impression about the communication knowledge and even form a preference for this media. Hence, if the communication of ICH popular science publication increases their dependence, the identification will also increase a lot.

\section{Conclusion}

In this article, the evaluation model of communication identification of ICH popular science publication is built on the basis of AHP and entropy method. According to data analysis from questionnaire, experts' opinion from interviews and field research, the weight of three levels' indexes is decided in the model. In conclusion, the factors at all the levels of use and identification affect audience identification in the evaluation model of communication identification of ICH popular science publication. Among these factors, audience from whom to know this channel, acquiring knowledge and integrating into relevant situation of skills and knowledge, these three indicators have the most significant influence on the communication identification of ICH popular science publication.

\section{References}

[1] Larson, L.C. (2010) Digital Readers: The Next Chapter in E-Book Reading and Response. The Reading Teacher, 64, 15-22.

http://onlinelibrary.wiley.com/doi/10.1598/RT.64.1.2/full https://doi.org/10.1598/RT.64.1.2

[2] Dewah, J.T. (2015) Making Gaborone a Stop and Not a Stop-Over: A Heritage and Cultural Tourism Destination. Doctoral Dissertation. http://www.repository.up.ac.za/handle/2263/50877

[3] Landriani, L. and Pozzoli, M. (2013) Management and Valuation of Heritage Assets: A Comparative Analysis between Italy and USA. Springer Science \& Business Media, Berlin.

[4] Schmitt, T.M. (2008) The UNESCO Concept of Safeguarding Intangible Cultural Heritage: Its Background and Marrakchi Roots. International Journal of Heritage Studies, 14, 95-111.

http://www.tandfonline.com/doi/abs/10.1080/13527250701844019 https://doi.org/10.1080/13527250701844019

[5] Lenzerini, F. (2011) Intangible Cultural Heritage: The Living Culture of Peoples. European Journal of International Law, 22, 101-120. https://academic.oup.com/ejil/article/22/1/101/436591/Intangible-Cultural-Heritage -The-Living-Culture-of https://doi.org/10.1093/ejil/chr006

[6] Russo, M., Ghose, R. and Mattioli, M. (2013) Networks-of-Stories to Value Tangible and Intangible Heritage in Museums. Digital Heritage International Congress, Marseille, 28 October-1 November 2013, Vol. 1, 451-451. https://iris.unimore.it/retrieve/handle/11380/992318/41512/Poster_246.pdf https://doi.org/10.1109/DigitalHeritage.2013.6744813 
[7] Ibrahim, N., Ali, N.M. and Yatim, N.F.M. (2011) Cultural Learning in Virtual Heritage: An Overview. In: International Visual Informatics Conference, Springer, Berlin, Heidelberg, 273-283.

https://link.springer.com/10.1007\%2F978-3-642-25200-6_26

[8] Artese, M.T. and Gagliardi, I. (2012) Cataloging Intangible Cultural Heritage on the Web. In: Euro-Mediterranean Conference, Springer, Berlin, Heidelberg, 676-683. https://link.springer.com/chapter/10.1007/978-3-642-34234-9_71

[9] Severo, M. and Venturini, T. (2016) Intangible Cultural Heritage Webs: Comparing National Networks with Digital Methods. New Media \& Society, 18, 1616-1635. http://journals.sagepub.com/doi/abs/10.1177/1461444814567981 https://doi.org/10.1177/1461444814567981

[10] Giaccardi, E. and Palen, L. (2008) The Social Production of Heritage through CrossMedia Interaction: Making Place for Place-Making. International Journal of Heritage Studies, 14, 281-297.

http://www.tandfonline.com/doi/abs/10.1080/13527250801953827 https://doi.org/10.1080/13527250801953827

[11] Blumler, J.G. and Katz, E. (1974) The Uses of Mass Communications: Current Perspectives on Gratifications Research. Sage Annual Reviews of Communication Research, Volume 3. https://eric.ed.gov/?id=ED119208

[12] Mon, D.L., Cheng, C.H. and Lin, J.C. (1994) Evaluating Weapon System Using Fuzzy Analytic Hierarchy Process Based on Entropy Weight. Fuzzy Sets and Systems, 62, 127-134.

http://www.sciencedirect.com/science/article/pii/0165011494900523

[13] Badri, M., Al Qubaisi, A., Mohaidat, J., et al. (2016) An Analytic Hierarchy Process for School Quality and Inspection: Model Development and Application. International Journal of Educational Management, 30, 437-459.

http://www.emeraldinsight.com/doi/full/10.1108/IJEM-09-2014-0123 https://doi.org/10.1108/IJEM-09-2014-0123

Submit or recommend next manuscript to SCIRP and we will provide best service for you:

Accepting pre-submission inquiries through Email, Facebook, LinkedIn, Twitter, etc. A wide selection of journals (inclusive of 9 subjects, more than 200 journals)

Providing 24-hour high-quality service

User-friendly online submission system

Fair and swift peer-review system

Efficient typesetting and proofreading procedure

Display of the result of downloads and visits, as well as the number of cited articles

Maximum dissemination of your research work

Submit your manuscript at: http://papersubmission.scirp.org/

Or contact jss@scirp.org 